\title{
Young People Purchasing Virtual Goods in Virtual Worlds: The Role of User Experience and Social Context
}

\author{
Matti Mäntymäki ${ }^{1, *}$, Jani Merikivi ${ }^{2}$, and A.K.M. Najmul Islam ${ }^{1}$ \\ ${ }^{1}$ Turku School of Economics, University of Turku, Finland \\ \{matti.mantymaki, najmul.islam\}@utu.fi \\ ${ }^{2}$ Aalto University, School of Business, Finland \\ jani.merikivi@aalto.fi
}

\begin{abstract}
Millions of young people spend real money on virtual goods such as avatars or in-world currency. Yet, limited empirical research has examined their shopping behaviour in virtual worlds. This research delves into young consumers' virtual goods purchasing behaviour and the relevance of social context and usage experience. We assert that virtual goods purchasing behaviour is inseparable of the online platform in which it is taking place. We employ the concept of cognitive absorption to capture the user experience and examine the social context with three variables, the size of one's in-world network, trust in the other users of the online platform and social presence. We test our research model with data collected from 1,225 virtual world users and use PLS in the analysis. The results show that virtual goods purchasing behaviour is predicted by cognitive absorption, perceived size of one's in-world network as well as trust in the other users.
\end{abstract}

Keywords: virtual worlds, virtual goods, cognitive absorption, trust.

\section{Introduction}

Purchasing virtual goods has become increasingly pervasive among the young generations. Virtual goods (e.g., avatars) are non-physical in nature and exist in the online platforms they are created in [1]). That is, they cannot be carried off to and used in another online platform. This characteristic separates virtual goods from digital goods (e.g., audio files which work in many platforms). While virtual goods have existed as long as virtual worlds (VWs), they did not receive attention before VW operators started to sell them to users with real money.

Interestingly, many of the current VWs are targeted for users aged between 5 and 15 years, who make the majority of over 1.4 billion registered VW users [2]. The large user base has made the overall spending on virtual goods to reach $\$ 15$ billion already in $2012 .^{1}$

Despite the economic potential, the research on virtual goods purchasing behaviour

\footnotetext{
* Corresponding author.

${ }^{1}$ (http: / /www. superdataresearch.com/blog/monetization-is-a-fourletter-word/)
} 
in VWs is still in its infancy- compared to the 'traditional' online shopping or that which occurs offline. To contribute to virtual goods research we seek to fill three gaps in the current literature. First, prior literature on virtual goods has focused rather heavily on adult consumers, albeit young people admittedly make a notable group of existing consumers. For example, young people have been under-investigated in information systems research [3].

With regard to the second gap, we advance virtual goods research by building on user experience. We believe this is of considerable importance since purchasing virtual goods requires engagement in online platforms where the goods are available. To this end, we employ cognitive absorption, which is an established driver of technology use, also in VWs [4; 5]. Notwithstanding, its influence on purchasing behaviour has remained poorly understood.

Third, we center on social context. While social context is demonstrated as critical for online platform success [6], studies on virtual goods fall short in examining its effect on purchasing behavior [7]. In this paper, we conceptualize social context to operate through perceived network size, social presence, and trust-all of which we consider relevant for virtual goods exchange.

By filling these gaps, we add on to three different research areas, virtual goods purchasing behavior [7; 8; 9], young users use of information technology [3], and the relationship between virtual goods and platforms where they are exchanged $[10 ; 11]$.

The paper is organized as follows. It starts with a literature revive and provide a foundation for the research model. The paper will then explicate the research model and hypotheses. This is followed by the methods and results. Lastly, it concludes with a discussion, including implications, limitations and suggestions for future research.

\section{Research Background and Hypotheses}

\subsection{Prior Literature on Virtual Purchasing Behavior}

Prior VW research has largely examined user adoption $\quad[12 ; 13 ; 14]$, including initial acceptance and post-adoption use $[4 ; 15 ; 16 ; 17 ; 18 ; 19]$. Purchasing behavior, in turn, has received less empirical research attention [20]. The prior research on the topic has found purchasing in VWs have being affected by the virtual environment [7], user motivation [1;8] and social influences [8].

Here we focus on two aspects that have drawn less attention in the VW, namely user experience and social context. They supplement each other as user experience stresses the experience obtained by an individual and social context the environment which is co-created by individual users. Social context is also expected to influence the individual's behavior [21]. Given virtual goods purchasing behavior is fairly inseparable of VW use we believe social context and user experience fit in perfectly to our research goal.

\subsection{The Research Model}

The user experience of VWs can be characterized with three key aspects. First, VWs employ avatars as a core of the navigation mechanisms and to represent the users. Second, VWs accommodate a multi-user, 3D graphical environment that includes 
sounds and music. Third, the user interface is highly dynamic because of a constant influx of new features and activities to sustain users' interest. Thus, the richness of stimuli that make the user absorbed in the in-world activities lie in the core of the VW user experience. Hence, we employ the concept of cognitive absorption. Cognitive absorption consists of focused immersion, intrinsic motivation, perception of control, temporal dissociation and curiosity. We measure it as a multi-dimensional construct as it was originally developed [22].

We also scrutinize how the social context can influence virtual purchasing behaviour. The social context is essentially dependent on the number of users involved in the VW. The social interaction, and the value users derive from it, is influenced by network externalities [19]. This is articulated in Metcalfe's law that postulates that the value of a telecommunications network is proportional to the square of the number of connected users [23]. For an individual user, however, the value of interactive digital technologies is more dependent upon the presence of relevant people, i.e. the user's personal network, than the network size in general $[19 ; 24]$. From a sociological perspective, this can be explained by the concept of homophily, i.e. the tendency to bond and associate with individuals with whom one perceives similarity [25]. Prior evidence from computer-mediated communication shows that interaction that involves the use of IT is likely to occur with key interpersonal relationships [26]. Thus, network externalities stem particularly from the presence of one's key social network in the VW.

In addition to the presence of other users and an in-world social network, the social atmosphere and the relationships between users represent important aspects of the social context. For example, people tend to communicate more when they perceive human warmth and psychological presence [27]. As a result, we examine the degree of human warmth and contact associated with the VW using the concept of social presence [28]. Trust is fundamental component of interpersonal relationships and an important predictor of online purchasing [29]. Hence, we investigate the trust in other VW users as a predictor of virtual purchasing. The constructs with their definitions and references are presented in Table1.

Table 1. The Research constructs and their definitions

\begin{tabular}{|l|l|l|}
\hline Construct & Definition & Source \\
\hline $\begin{array}{l}\text { Perceived } \\
\text { enjoyment }\end{array}$ & $\begin{array}{l}\text { The degree of enjoyment associated with using the } \\
\text { VW. }\end{array}$ & {$[22]$} \\
\hline $\begin{array}{l}\text { Focused } \\
\text { immersion }\end{array}$ & $\begin{array}{l}\text { The experience of total engagement where other } \\
\text { attentional demands are, in essence, ignored. }\end{array}$ & {$[22]$} \\
\hline $\begin{array}{l}\text { Perception of } \\
\text { control }\end{array}$ & $\begin{array}{l}\text { The user's perception of being in charge of the } \\
\text { interaction. }\end{array}$ & {$[22]$} \\
\hline $\begin{array}{l}\text { Temporal } \\
\text { dissociation }\end{array}$ & $\begin{array}{l}\text { The inability to register the passage of time while } \\
\text { engaged in interaction. }\end{array}$ & {$[22 ; 30]$} \\
\hline Curiosity & $\begin{array}{l}\text { The extent the experience arouses an individual's } \\
\text { sensory and cognitive curiosity. }\end{array}$ & {$[22]$} \\
\hline $\begin{array}{l}\text { Perceived network } \\
\text { size }\end{array}$ & $\begin{array}{l}\text { The perception of the degree to which important others } \\
\text { are present in the VW. }\end{array}$ & {$[16 ; 31]$} \\
\hline Social presence & The degree of human warmth associated with the VW. & {$[28 ; 32]$} \\
\hline User-to-user trust & The belief in the other VW users' honesty. & {$[29]$} \\
\hline
\end{tabular}


The research model accommodating the user experience and social context is presented in Figure 1 below.

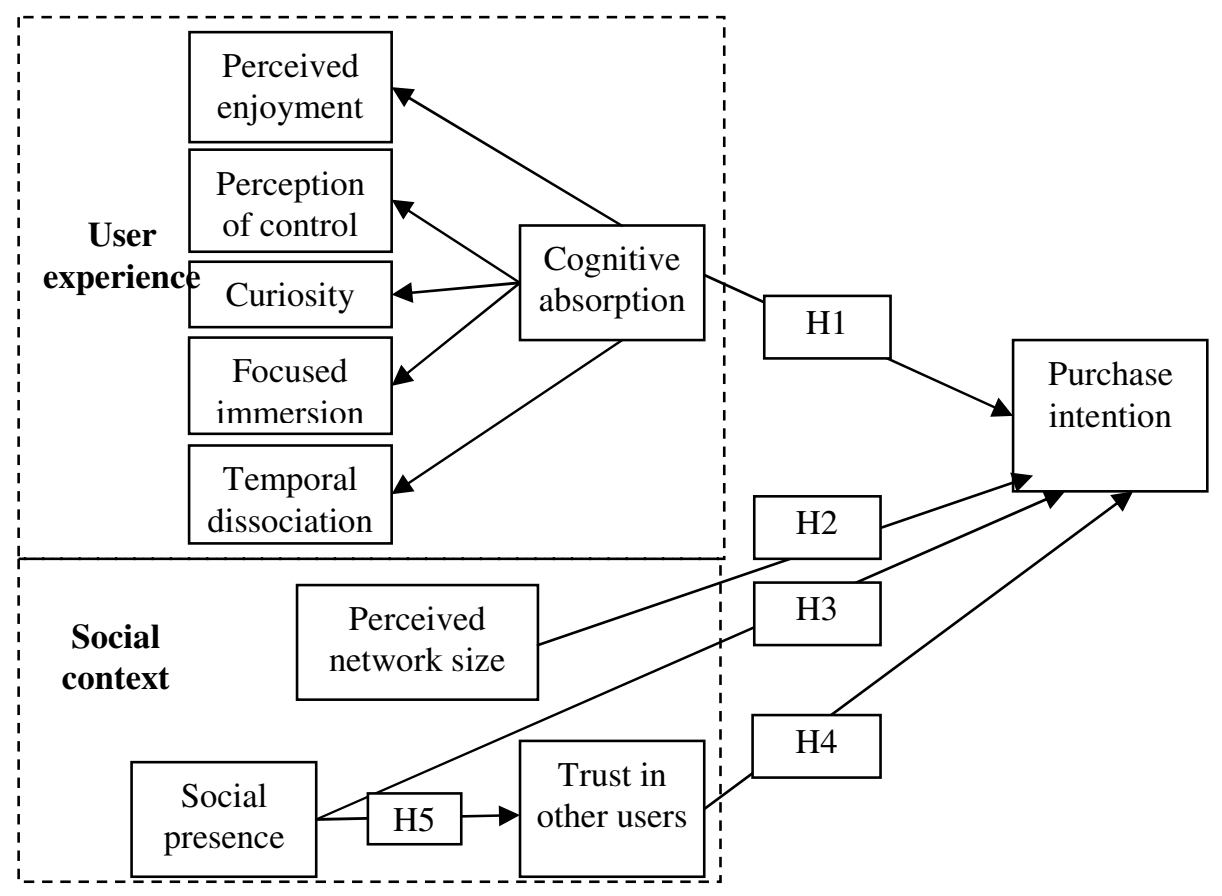

Fig. 1. The Research model

\subsection{Hypotheses}

Agarwal and Karahanna [22] positioned cognitive absorption as a predictor of perceived usefulness and ease of use but did not examine its direct effect on behavioural intention. Cognitive absorption is an intrinsically motivating state [33], enjoyment being one of its dimensions [22]. Intrinsic motivation, often captured with perceived enjoyment, in turn has been found to predict the intention to adopt and use various forms of IT, particularly those of hedonic nature [34; 35]. Prior VW research offers empirical support for the link between cognitive absorption and behavioural intention $[4 ; 5]$. As a result, we assume that the purchase intention is influenced by cognitive absorption and put forward the following hypothesis:

H1: Cognitive absorption has a positive effect on purchase intention.

Due to network externalities (Katz \& Shapiro, 1986), the size of one's personal network inside the VW influences the amount of opportunities the user has for social interaction and communication. Furthermore, a large social circle in an VW provides more opportunities to demonstrate status through virtual purchasing or when trading virtual items with other users. Prior research on online social networking [36], instant messaging [24] and VWs [16] offers empirical evidence that the perceived size of user's network predicts the usage intention. 
H2: Perceived aggregate network exposure has a positive effect on purchase intention.

Social presence has been found to have a positive effect on loyalty in the online shopping context [37]. Furthermore, previous VW research has shown a positive relationship between social presence and favourable attitudes [38] and user satisfaction [15]. However, the research has reported no relationship between social presence and behavioural intention $[7 ; 15]$.

H3: Social presence has a positive effect on purchase intention.

Abundant research on e-commerce has verified a positive relationship between trust in the online merchant and user's purchasing behaviour [39]. However, considerably fewer studies have examined to what extent the trust between users affects purchasing, especially in an environment where the users are represented as avatars. Lu et al. [40] reported a positive relationship between intentions to purchase from the website and member-to-member trust.

H4: Trust in other users of the VW has a positive effect on purchase intention.

Social presence has been found to increase the number of messages exchanged in electronic communication [27]. As VWs are information-rich environments that are well capable of transmitting various non-verbal cues [15], we propose a positive relationship between social presence and trust in the other VW users. This assertion is also in accordance with the e-commerce literature that has reported social presence to have a positive effect on trust $[32 ; 41]$.

H5: Social presence has a positive effect on trust in the other users of the VW.

\section{Empirical Research}

\subsection{Data Collection and Measurement}

The data was collected through an online survey among the users of the Finnish Habbo Hotel portal in co-operation with Sulake Corporation, the Finnish company that owns and operates Habbo Hotel.

The survey was opened 8,928 times. 3,265 respondents proceeded to the final page and submitted the survey. This yielded a response rate of 36.6 percent. To further ensure the reliability of the results only fully completed questionnaires were included in the analysis. As a result, the final sample consisted of 1,225 responses. 60.8 per cent of the final sample was female.

To ensure the reliability of the measurement, the survey items were adopted from prior literature with wording adjusted to match the VW context and the target audience. The literature references of the measurement items were presented in Table 2. The items were measured with a seven-point Likert scale, anchored from strongly disagree to strongly agree - except perceived network size, which was measured with semantic scale. The constructs were modeled using reflective indicators. 


\subsection{Data Analysis}

The data was analysed using partial least squares with smartPLS software [42]. We began the analysis by testing the convergent and discriminant validity of the measurement model. Convergent validity was evaluated based on three criteria [43]: firstly, all indicator factor loadings should be significant and exceed 0.70. Secondly, composite reliabilities should exceed 0.80 . Thirdly, average variance extracted (AVE) by each construct should be greater than 0.5 . Appendix A illustrates that the data met the criteria for convergent validity. With respect to discriminant validity, the AVE for each construct should exceed the squared correlation between that and any other construct [43]. Table 3 shows that discriminant validity was confirmed.

Table 2. Squared correlation between constructs (AVEs in bold in the main diagonal)

\begin{tabular}{|llllllllll|}
\hline & CON & CTRL & CUR & ENJ & PNS & PURC & SP TDIS & TRU \\
\hline CON & $\mathbf{0 . 7 4 9}$ & & & & & & & & \\
CTRL & 0.064 & $\mathbf{0 . 8 1 2}$ & & & & & & & \\
CUR & 0.305 & 0.101 & $\mathbf{0 . 8 6 4}$ & & & & & & \\
ENJ & 0.328 & 0.158 & 0.524 & $\mathbf{0 . 8 8 9}$ & & & & & \\
PNS & 0.115 & 0.050 & 0.265 & 0.222 & $\mathbf{0 . 8 2 6}$ & & & & \\
PURC & 0.182 & 0.077 & 0.282 & 0.303 & 0.257 & $\mathbf{0 . 8 6 4}$ & & & \\
SP & 0.219 & 0.142 & 0.359 & 0.422 & 0.211 & 0.241 & $\mathbf{0 . 7 9 9}$ & & \\
TDIS & 0.386 & 0.070 & 0.468 & 0.416 & 0.177 & 0.218 & 0.272 & $\mathbf{0 . 7 1 6}$ & \\
TRU & 0.139 & 0.035 & 0.276 & 0.234 & 0.270 & 0.247 & 0.269 & 0.172 & $\mathbf{0 . 9 0 7}$ \\
\hline
\end{tabular}

After having verified the validity and reliability of the measurement model, we proceeded to testing the structural model. According to Agarwal \& Karahanna (2000), cognitive absorption was modeled as a second order construct. Bootstrapping with 1,000 subsamples was used to estimate the significance of the path coefficients. The latent variable scores of its five constituting factors were used as an input to build the second order variable.

The $\mathrm{R}^{2}$ of purchase intention was 42.7 per cent, which indicates that the model as a whole exerts good predictive validity. As the sample size was large, instead of looking strictly the significance of the path coefficients, we considered the value of 0.1 as a threshold to interpret that a variable exerts a substantial effect on its endogenous construct [44]. Based on this criterion, all hypotheses were supported except H3. Age, gender and length of usage experience with the VW were included in the structural model as control variables. None of the control variables exerted a significant influence on purchase intention. Figure 2 below summarizes the results from testing the structural model. 


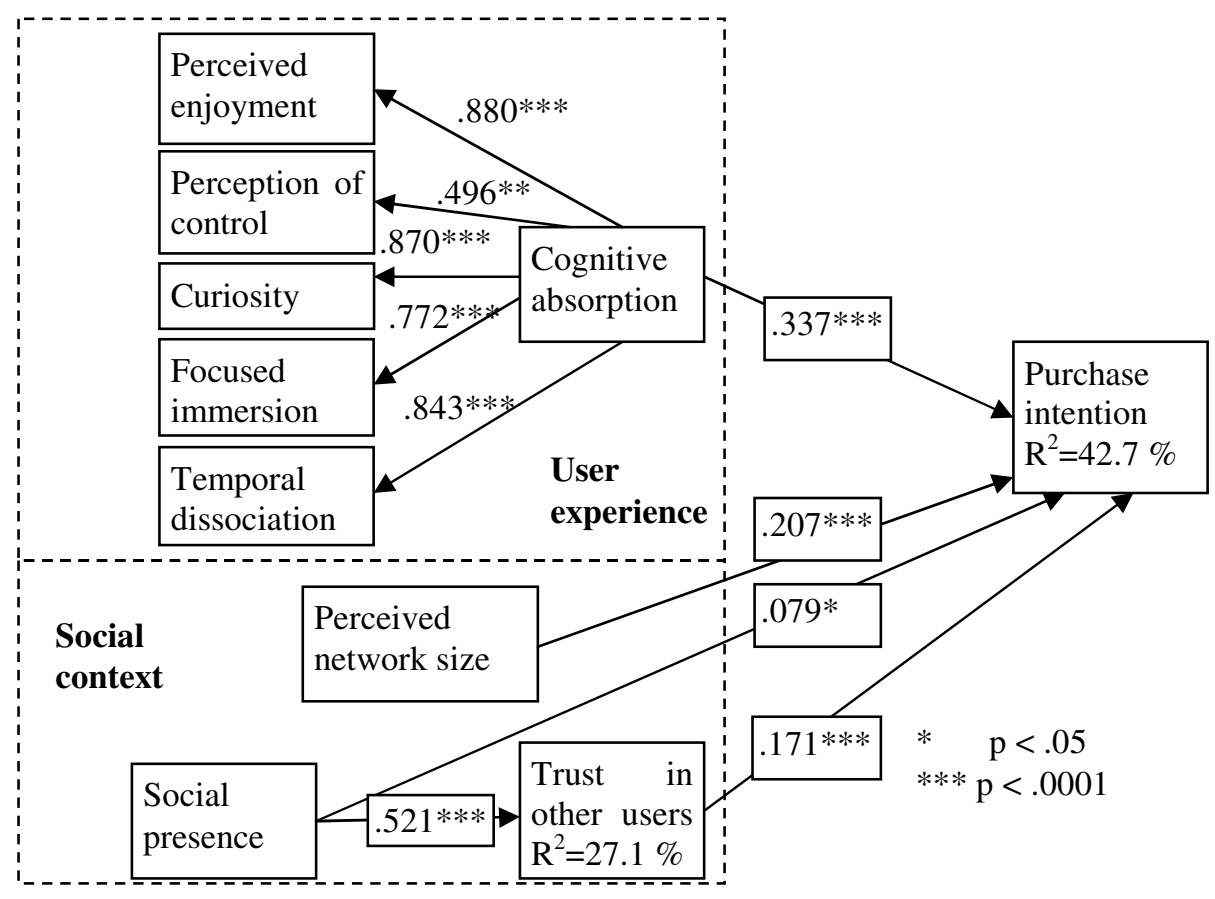

Fig. 2. Results of the PLS analysis

\section{Discussion and Conclusion}

The key finding of this study is that user experience captured through cognitive absorption and its first order constructs is the main driver of purchase intention. While prior research provided empirical evidence of user experience in driving usage [45] our results show that it has effect on purchase intention that takes place beyond usage. Overall, this finding implies that engaging user experience can drive VW operators' sales and thus it is critical for VWs success.

\subsection{Theoretical Implications}

Our results verify the importance of cognitive absorption as a component of the VW user experience and its value in predicting purchasing behaviour. On a more theoretical level, our conceptualization of cognitive absorption as a five-dimensional second order construct offers other researchers guidance how to capture the contextual characteristics of VWs. Based on our findings, virtual purchasing is substantially affected by the experiential aspects of VW usage, indicating that the user experience is a stable predictor of virtual purchasing across context [7] 
With regard to the social context, our findings show that purchasing behaviour is influenced by the size of user's in-world network and the trust experienced in other users of the VW. This indicates that network externalities play a role in virtual world participation [19]. Network externalities can thus affect the hedonic value extracted from the VW participation by offering more invitations to in-world events and parties. Furthermore, the status value [46] from possessing virtual items is likely to be dependent on the size of one's in-world social network.

Albeit social presence did exert hardly a marginal effect on purchase intention, it is a relative strong predictor of the trust between users. While the trust in other users influenced purchase intention, its role was not particularly salient. We assume that rather than having a linear relationship with purchase intention, trust may exert a threshold, thus being a prerequisite for purchasing to take place.

\subsection{Implications for Practice}

For VW operators and developers creating engaging experiences seems to be a way to reinforce in-world purchasing behaviour. This may indicate that purchasing results from sustained participation in the VW and can thus represent a subsequent stage in the development of the customer relationship. From this perspective, operators should focus on developing the customer relationships rather than utilizing tactical marketing tools to promote in-world purchasing.

Second, the results offer certain evidence that a trusting and psychologically warm social environment encourages purchasing behaviour. Thus, VWs operators are advised to have mechanisms not only to protect users' virtual property, but to prevent aggressive behaviour and communication towards other users.

Third, we suggest operators should take a close look at how the presence and actions of other users within and beyond the VW affect users' participation and purchasing decisions. Young people have been reported to follow fads and fashion and thus be more prone to bandwagon effect than older generations [47]. This can partly explain the dynamics of the social setting and sometimes very short lifespans of trends in the VW for the young.

\subsection{Limitations and Future Research}

First, due to our research context, generalizability of the results is limited. Second, we examined behavioural intention instead of actual behaviour. Third, we used three constructs, perceived network size, social presence and trust in other users to examine the social context. Due to its conceptual breath, social context is very difficult to condense into a set of variables. We recommend further research to offer a richer understanding of the social context and structures behind the behavioural outcomes such as virtual purchasing. For example, future research could examine the interplay between the social context and purchasing behaviour [21].

Fourth, in our conceptualization of trust we focused only on the trustworthiness, i.e. the reliability of other users. However, prior research has highlighted the complex, multi-faceted nature of trust

[29]. Moreover, in the VW context, the user may or 
may not trust in several entities such as the user community (or a specific subgroup within the community), the company operating the service and the service as a whole. Thus, research focusing particularly on the nature and dimensions of trust in the VW context would offer a better understanding of the social context of VWs and, at the same time, uncover the role of the avatar-centric environment in the formation of trust.

Finally, we used only the cognitive absorption to empirically examine the key aspects of the VW user experience. However, from VWs people do not necessary seek for immersion and intensive experiences but a relaxing place to spend time and socialise with other users in a casual manner. Hence, further research could examine to what extent the VW participation is perceived relaxing or stress-relieving.

\section{References}

1. Guo, Y., Barnes, S.J.: Explaining purchasing behavior within world of warcraft. Journal of Computer Information Systems 52(3), 18-30 (2012)

2. Wasko, M., Teigland, R., Leidner, D., Jarvenpaa, S.: Stepping into the internet: New ventures in virtual worlds. MIS Quarterly 35(3), 645-652 (2011)

3. Vodanovich, S., Sundaram, D., Myers, M.: Digital natives and ubiquitous information systems. Information Systems Research 21(4), 711-723 (2010)

4. Goel, L., Johnson, N.A., Junglas, I., Ives, B.: From space to place: Predicting users' intentions to return to virtual worlds. MIS Quarterly 35(3), 749-771 (2011)

5. Nevo, S., Nevo, D., Kim, H.: From recreational applications to workplace technologies: An empirical study of cross-context IS continuance in the case of virtual worlds. Journal of Information Technology 27(1), 74-86 (2012)

6. Merikivi, J., Mäntymäki, M.: Explaining the continuous use of social virtual worlds: An applied theory of planned behavior approach. In: Proceedings of the 42nd Hawaii Conference on System Sciences, Waikoloa, Big Island, Hawaii (2009)

7. Animesh, A., Pinsonneault, A., Yang, S.-B., Oh, W.: An odyssey into virtual worlds: Exploring the impacts of technological and spatial environments on intention to purchase virtual products. MIS Quarterly 35(3), 789-810 (2011)

8. Mäntymäki, M., Salo, J.: Purchasing behavior in social virtual worlds: An examination of habbo hotel. International Journal of Information Management 33(2), 282-290 (2013)

9. Guo, Y., Barnes, S.: Purchase behavior in virtual worlds: An empirical investigation in second life. Information \& Management 48(7), 303-312 (2011)

10. Payne, A.F., Storbacka, K., Frow, P.: Managing the co-creation of value. Journal of the Academy of Marketing Science 36(1), 83-96 (2008)

11. Füller, J.: Refining virtual co-creation from a consumer perspective. California Management Review 52(2), 98-122 (2010)

12. Hua, G., Haughton, D.: Virtual worlds adoption: A research framework and empirical study. Online Information Review 33(5), 889-900 (2009)

13. Fetscherin, M., Lattemann, C.: User acceptance of virtual worlds. Journal of Electronic Commerce Research 9(3), 231-242 (2008)

14. Shen, J., Eder, L.: Exploring intentions to use virtual worlds for business. Journal of Electronic Commerce Research 10(2), 94 (2009) 
15. Jung, Y.: Understanding the role of sense of presence and perceived autonomy in users' continued use of social virtual worlds. Journal of Computer-Mediated Communication 16(4), 492-510 (2011)

16. Mäntymäki, M., Salo, J.: Teenagers in social virtual worlds: Continuous use and purchasing behavior in habbo hotel. Computers in Human Behavior 27(6), 2088-2097 (2011)

17. Mäntymäki, M., Riemer, K.: Digital natives in social virtual worlds: A multi-method study of gratifications and social influences in habbo hotel. International Journal of Information Management 34(2), 210-220 (2014)

18. Mäntymäki, M., Merikivi, J., Verhagen, T., Feldberg, F., Rajala, R.: Does a contextualized theory of planned behavior explain why teenagers stay in virtual worlds? International Journal of Information Management 34(5), 567-576 (2014)

19. Mäntymäki, M., Islam, A.K.M.N.: Social virtual world continuance among teens: Uncovering the moderating role of perceived aggregate network exposure. Behaviour \& Information Technology 33(5), 536-547 (2014)

20. Mäntymäki, M.: Continuous use and purchasing behaviour in social virtual worlds. Turku School of Economics, Series A, Turku (2011)

21. Bandura, A.: Social foundations of thought and action: A social cognitive theory. Prentice Hall, Englewood Cliffs (1986)

22. Agarwal, R., Karahanna, E.: Time flies when you're having fun: Cognitive absorption and beliefs about information technology usage. MIS Quarterly 24(4), 665-694 (2000)

23. Shapiro, C., Varian, H. R.: In: Varian, H.R. (ed.), Information rules: A strategic guide to the network economy. Harvard Business School Press, Boston (1999)

24. Lin, C., Bhattacherjee, A.: Elucidating individual intention to use interactive information technologies: The role of network externalities. International Journal of Electronic Commerce 13(1), 85-108 (2008)

25. McPherson, M., Smith-Lovin, L., Cook, J.M.: BIRDS OF A FEATHER: Homophily in social networks. Annual Review of Sociology 27(1), 415 (2001)

26. Yuan, Y.C., Gay, G.: Homophily of network ties and bonding and bridging social capital in computer-mediated distributed teams. Journal of Computer-Mediated Communication, 11(4), Article 9 (2006)

27. Gefen, D.: Gender differences in the perception and use of E-mail: An extension to the technology acceptance model. MIS Quarterly 21(4), 389-400 (1997)

28. Short, J., Williams, E., Christie, B.: The social psychology of telecommunications. Wiley, London (1976)

29. McKnight, D.H., Choudhury, V., Kacmar, C.: Developing and validating trust measures for e-commerce: An integrative typology. Information Systems Research 13(3), 334-359 (2002)

30. Ahn, T., Ryu, S., Han, I.: The impact of web quality and playfulness on user acceptance of online retailing. Information \& Management 44(3), 263-275 (2007)

31. Guo, Y., Barnes, S.: Virtual item purchase behavior in virtual worlds: An exploratory investigation. Electronic Commerce Research 9(1-2), 77-96 (2009)

32. Gefen, D., Straub, D.W.: Consumer trust in B2C e-commerce and the importance of social presence: Experiments in e-products and e-services. Omega 32(6), 407-424 (2004)

33. Davis, F.D., Bagozzi, R.P., Warshaw, P.R.: Extrinsic and intrinsic motivation to use computers in workplace. Journal of Applied Social Psychology 22(14), 1111-1132 (1992)

34. van der Heijden, H.: User acceptance of hedonic information systems. MIS Quarterly 28(4), 695-704 (2004) 
35. Venkatesh, V., Thong, J.Y.L., Xu, X.: Consumer acceptance and use of information technology: Extending the unified theory of acceptance and use of technology. MIS Quarterly 36(1), 157-178 (2012)

36. Aggarwal, C.C., Yu, P.S.: On the network effect in web 2.0 applications. Electronic Commerce Research and Applications (forthcoming, available online)

37. Cyr, D., Hassanein, K., Head, M., Ivanov, A.: The role of social presence in establishing loyalty in e-service environments. Interacting with Computers 19(1), 43-56 (2007)

38. Schwarz, A., Schwarz, C., Jung, Y., Perez, B., Wiley-Patton, S.: Towards an understanding of assimilation in virtual worlds: The 3C approach. Eur. J. Inf. Syst (2011)

39. Ali, N.Y., Lo, T.Y.S., Auvache, V.L., White, P.D.: Bad press for doctors: 21 year survey of three national newspaper. Br. Med. J. 323(7316), 782-783 (2001)

40. Gefen, D., Karahanna, E., Straub, D.W.: Trust and TAM in online shopping: An integrated model. MIS Quarterly; Minneapolis 27(1), 51-90 (2003)

41. Lu, Y., Zhao, L., Wang, B.: From virtual community members to C2C e-commerce buyers: Trust in virtual communities and its effect on consumers' purchase intention. Electronic Commerce Research and Applications 26(4), 346-360 (2010)

42. Hassanein, K., Head, M.: Manipulating perceived social presence through the web interface and its impact on attitude towards online shopping. International Journal of Human-Computer Studies 65(8), 689-708 (2007)

43. Ringle, C.M., Wende, S., Will, A.: Smart PLS 2.0 M3. University of Hamburg (2005), http: / / www. Smartpls. De

44. Fornell, C., Larcker, D.F.: Evaluating structural equation models with unobservable variables and measurement error. Journal of Marketing Research 18(1), 39-50 (1981)

45. Chin, W.W.: Issues and opinion on structural equation modeling. MIS Quarterly \& The Society for Information Management (1998)

46. Islam, A.K.M.N., Mäntymäki, M.: Continuance of professional social networking sites: A decomposed expectation-confirmation approach. Paper 5 (2012)

47. Sheth, J.N., Newman, B.I., Gross, B.L.: Why we buy what we buy: A theory of consumption values. Journal of Business Research 22(2), 159-170 (1991)

48. Kastanakis, M.N., Balabanis, G.: Between the mass and the class: Antecedents of the "bandwagon" luxury consumption behavior. Journal of Business Research 65(10), 1399-1407 (2012) 


\section{Appendix A. Convergent Validity}

\begin{tabular}{|c|c|c|c|c|}
\hline Item & Operationalization & Load & C.R. & Alpha \\
\hline $\begin{array}{l}\text { CON1 } \\
\text { CON2 } \\
\text { CON3 } \\
\text { CON4 }\end{array}$ & $\begin{array}{l}\text { I was absorbed intensively in the activity in } \\
\text { Habbo } \\
\text { My attention was focused on the activity in } \\
\text { Habbo } \\
\text { I concentrated fully on the activity in Habbo } \\
\text { I was deeply engrossed in the activity in Habbo }\end{array}$ & $\begin{array}{l}0.896 \\
0.910 \\
0.837\end{array}$ & 0.923 & 0.890 \\
\hline $\begin{array}{l}\text { ENJ1 } \\
\text { ENJ2 } \\
\text { ENJ3 }\end{array}$ & $\begin{array}{l}\text { It is enjoyable to use Habbo } \\
\text { It is fun to use Habbo } \\
\text { It is entertaining to use Habbo }\end{array}$ & $\begin{array}{l}0.931 \\
0.950 \\
0.947\end{array}$ & 0.960 & 0.937 \\
\hline $\begin{array}{l}\text { TDIS1 } \\
\text { TDIS2 } \\
\text { TDIS3 }\end{array}$ & $\begin{array}{l}\text { When using Habbo, time goes by fast } \\
\text { When using Habbo, I am not aware of any } \\
\text { noise } \\
\text { When using Habbo, I often forget the work I } \\
\text { must do }\end{array}$ & $\begin{array}{l}0.822 \\
0.874\end{array}$ & 0.883 & 0.802 \\
\hline $\begin{array}{l}\text { CUR1 } \\
\text { CUR2 }\end{array}$ & $\begin{array}{l}\text { Using Habbo increases my interest in exploring } \\
\text { things } \\
\text { Using Habbo arouses my imagination }\end{array}$ & $\begin{array}{l}0.932 \\
0.927\end{array}$ & 0.927 & 0.842 \\
\hline $\begin{array}{l}\text { SP1 } \\
\text { SP2 } \\
\text { SP3 }\end{array}$ & $\begin{array}{l}\text { There is a sense of human contact in Habbo } \\
\text { There is a sense of sociability in Habbo } \\
\text { There is a sense of human warmth in Habbo }\end{array}$ & $\begin{array}{l}0.859 \\
0.910 \\
0.913\end{array}$ & 0.923 & 0.875 \\
\hline $\begin{array}{l}\text { TRU1 } \\
\text { TRU3 } \\
\text { TRU3 }\end{array}$ & $\begin{array}{l}\text { I believe that the other Habbo users always } \\
\text { keep their promises } \\
\text { I believe the other Habbo users are honest } \\
\text { I believe in the other users' integrity }\end{array}$ & $\begin{array}{l}0.934 \\
0.961 \\
0.960\end{array}$ & 0.967 & 0.948 \\
\hline $\begin{array}{l}\text { CTRL1 } \\
\text { CTRL2 }\end{array}$ & $\begin{array}{l}\text { I have the resources, knowledge, and ability to } \\
\text { use Habbo } \\
\text { Using Habbo is entirely within my control }\end{array}$ & $\begin{array}{l}0.891 \\
0.911\end{array}$ & 0.896 & 0.769 \\
\hline $\begin{array}{l}\text { PNS1 } \\
\text { PNS2 } \\
\text { PNS3 }\end{array}$ & $\begin{array}{l}\text { How many people about your age use Habbo? } \\
\text { none... all } \\
\text { How many of your friends use Habbo? } \\
\text { none... all } \\
\text { How many of your peers use Habbo? } \\
\text { none... all }\end{array}$ & $\begin{array}{l}0.898 \\
0.895\end{array}$ & 0.934 & 0.894 \\
\hline $\begin{array}{l}\text { PURC1 } \\
\text { PURC2 } \\
\text { PURC3 }\end{array}$ & $\begin{array}{l}\text { I intend to purchase Habbo items and/or Habbo } \\
\text { Club memberships* shortly } \\
\text { I predict I will purchase Habbo items and/or } \\
\text { Habbo Club memberships in the short term } \\
\text { I will frequently purchase Habbo items and/or } \\
\text { Habbo Club memberships in the future }\end{array}$ & 0.939 & 0.950 & 0.921 \\
\hline
\end{tabular}

* Habbo Club membership refers to a package, which includes exclusive virtual goods such as clothing and furniture. 